\title{
Corpus Uteri
}

National Cancer Institute

\section{Source}

National Cancer Institute. Corpus Uteri. NCI Thesaurus. Code C12316.

The Corpus uteri, or body of uterus, is the part of the uterus above the isthmus, comprising about two thirds of the non-pregnant organ. 